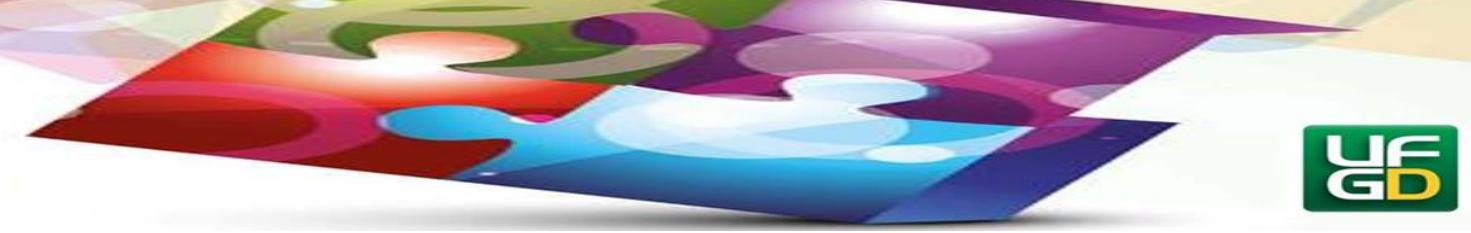

\title{
RELATO DE EXPERIÊNCIA: PROJETO OLHOS DA ALMA
}

\section{EXPERIENCE REPORT: PROJECT EYES OF THE SOUL}

\author{
Felipe Nascimento TEIXEIRA ${ }^{1}$ \\ Rafael de Paulo COELHO ${ }^{2}$ \\ Uiara Lima FARIAS ${ }^{3}$ \\ Natália Cristina de OLIVEIRA ${ }^{4}$
}

\begin{abstract}
Resumo: em nossa sociedade, a deficiência não é mais considerada um assunto novo. Antigamente, os tratamentos que essas pessoas recebiam revelavam a falta de entendimento sobre o assunto. Em décadas mais recentes, pessoas com deficiência obtiveram grandes vitórias, especialmente os deficientes visuais. No meio acadêmico, muito pouco se tem estudado a respeito de modalidades esportivas de luta para esta população. Com o intuito de contribuir para o preenchimento desta lacuna, o objetivo deste trabalho foi descrever a metodologia de ensino e treinamento de Muay Thai para deficientes visuais, realizada no projeto "Olhos da Alma". Para isso, foi gravada uma entrevista com o profissional responsável pelo projeto e com uma de suas alunas. $\mathrm{O}$ ensino da modalidade possui metodologia específica para os deficientes visuais, desenvolvida pelo profissional. Os movimentos foram divididos em partes, e as sequências sistematizadas. Algumas técnicas foram desenvolvidas para possibilitar o aprendizado da modalidade pelos deficientes visuais, entretanto, nenhuma adaptação precisou ser feita nos equipamentos normalmente utilizados nos treinos de Muay Thai. A participação no projeto, de acordo com a percepção do profissional e da aluna, contribui para a inclusão social, melhora do condicionamento físico, da socialização e da autoestima dos alunos com deficiência visual.
\end{abstract}

Palavras-chave: Deficiência Visual. Esportes de Luta. Educação Física e Treinamento.

Abstract: in our society, disability is no longer considered a new issue. In the past, treatments these people received revealed a lack of understanding on the subject. In recent decades, people with disabilities achieved great victories, especially the visually impaired ones. In academic circles, very little has been studied regarding wrestling modalities for this population. In order to contribute to filling this gap, the aim of this study was to describe the teaching methodology of Muay Thai training for visually impaired held on the project "Eyes of the Soul". For this, we recorded an interview with the professional responsible for the project and one of his pupils.

\footnotetext{
${ }^{1}$ Profissional de Educação Física graduado pelo Centro universitário Adventista de São Paulo (UNASP). Email: felipeselby@gmail.com.

${ }^{2}$ Profissional de Educação Física graduado pelo Centro universitário Adventista de São Paulo (UNASP). Email: rafaeldepaulocoelho1@ hotmail.com.

${ }^{3}$ Profissional de Educação Física graduada pelo Centro universitário Adventista de São Paulo (UNASP). Email: uiaralind@hotmail.com.

${ }^{4}$ Docente e Pesquisadora do Mestrado Profissional em Promoçãoda Saúde e da Graduação em Educação Física.

Centro Universitário Adventista de São Paulo (UNASP). Email: nataliaovs@gmail.com.
} 


\section{HORIZONTES - REVISTA DE EDUCACÃOO}

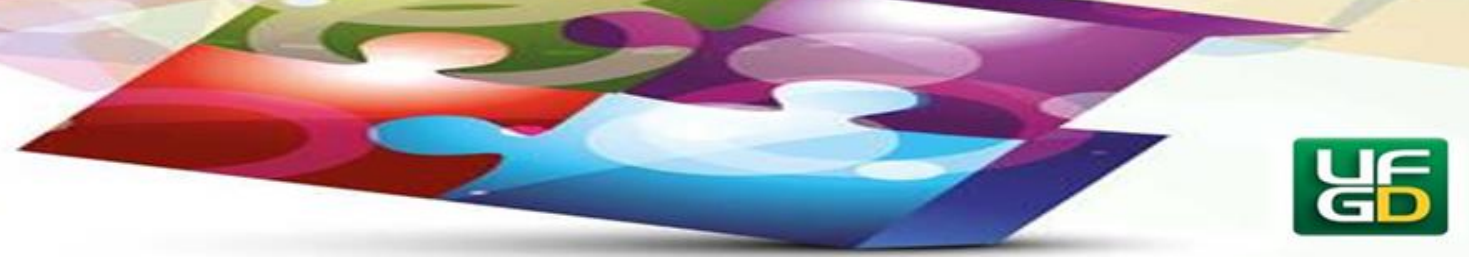

To teach the modality, a specific methodology for the visually impaired was developed by the professional. Movements were divided in parts and sequences were systematized. Some techniques have been developed to enable learning by the visually impaired, however, no adjustment had to be made in the equipment usually employed in Muay Thai practice. Participation in the project, according to professional's and pupil's perception, contributes to social inclusion, improvement of fitness, socialization and self-esteem of participants with visual impairment.

Keywords: Vision Disorders. Wrestling. Physical Education and Training.

\section{Introdução}

A população de pessoas deficientes vem crescendo a cada ano no Brasil, e segundo a Cartilha do Censo 2010 (OLIVEIRA, 2012), 23,9\% da população brasileira tem algum tipo de deficiência. Destes, $18,6 \%$ têm deficiência visual, severa ou não.

A deficiência não é algo novo em meio à nossa sociedade. Os tratamentos que os deficientes recebiam na antiguidade revelam a falta de conhecimento que se tinha sobre o assunto. As pessoas com deficiência, seja ela qual fosse, eram vistas pela sociedade com pena e piedade, como pessoas castigadas pelos deuses, sendo assim abandonadas e rejeitadas (ARAÚJO et al., 2008). Esse pensamento era defendido pela sociedade em geral, incluindo pensadores e pessoas importantes, como Platão e Aristóteles, que defendiam a eliminação das crianças com deficiência (ARAÚJO et al., 2008).

Em décadas mais recentes, as pessoas com deficiência tiveram muitas vitórias importantes, em específico no caso dos deficientes visuais. Um exemplo brasileiro é, o Instituto Benjamin Constant (IBC) que deu início em 1854 ao atendimento educacional para cegos, e o faz até os dias de hoje (VIEIRA, 1998). Apesar de alguns avanços, ainda existem barreiras a serem ultrapassadas, especialmente relacionadas àinclusão social das pessoas com deficiência (COSTA e SOUZA, 2004). Um aliado muito forte para a inclusão social do portador de deficiência visual pode ser o esporte (LABRONICI et al., 2000).

Segundo Pereira et al (2013, p. 97):

A prática esportiva contribui para a sociabilização da pessoa com deficiência na medida em que facilita a comunicação, a realização pessoal, a autoimagem, autoconceito e a autonomia, além de relativizar suas limitações, uma vez que valoriza e divulga as suas capacidades físicas. Promove assim uma acentuação das capacidades em desfavor das limitações. O desporto também reforça a 


\section{HORIZONTES - REVISTA DE EDUCAÇÃO}

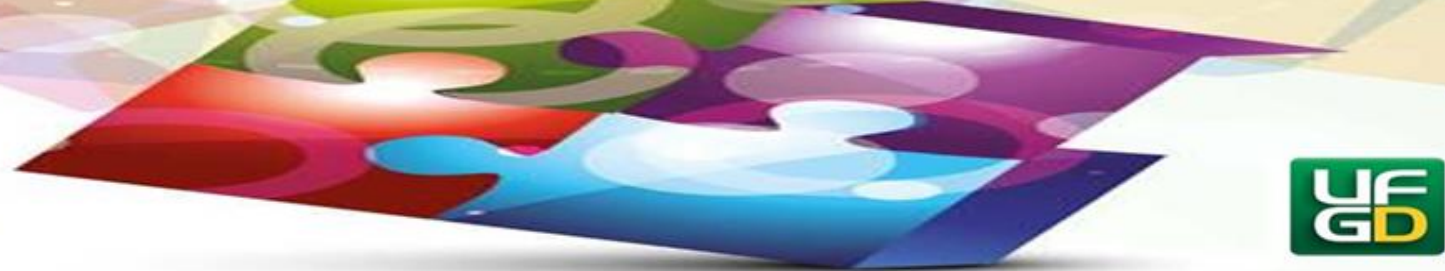

autoestima, dando-lhe alegria de viver, melhorando a qualidade de vida, favorecendo a comunicação e o convívio social.

Outro autor também aponta para os benefícios da prática esportiva no desenvolvimento das pessoas com deficiência visual, o que reflete nas capacidades motoras e cognitivas, na qualidade de vida e no cotidiano dessas pessoas (MACIEL, 2000).

Dentro do universo acadêmico, pouco se estuda a respeito da temática de lutas, e é bastante inexpressiva a quantidade de trabalhos que abordam sua relação com as deficiências. Além disso, estudo recente realizado com atletas portadores de deficiência aponta que essas pessoas esperam um preparo adequado do profissional de Educação Física, e que, além de conhecimento, eles sejam comprometidos e compreensivos em relação às questões relacionadas à atividade física adaptada (MAGALHÃES et al., 2014). Nesse contexto, o projeto "Olhos da Alma" foi criado pelo profisssional de Educação Física Alex Paraná, há um ano e meio atrás, com o objetivo de incluir os alunos com deficiência visual na modalidade MuayThai, visando à maior inclusão social destas pessoas.

Assim, o objetivo desse trabalho foi descrever o método de ensino e treinamento de MuayThai para deficientes visuais, no projeto "Olhos da Alma", visando contribuir para o aumento do conhecimento na área da Educação Física adaptada, particularmente no que diz respeito às lutas e aos deficientes visuais.

\section{Metodologia}

Quanto aos procedimentos de pesquisa optou-se pelo relato de experiência, tendo como objeto de estudo o "Projeto Olhos da Alma" que vem sendo desenvolvido em Cuiabá-MT.

Foi realizada visita ao projeto em setembro de 2015. O profissional de Educação Física e mestre em Muay Thai Alex Paraná, idealizador responsável pelo projeto, e a aluna Luiza Ferreira Sobrinho Arruda Santos, autorizaram a gravação de áudio e vídeo da entrevista e de uma das aulas, e sua utilização para fins acadêmico-científicos.

O roteiro da entrevista (apêndice) visou conhecer e analisar o método de ensino do referido projeto, bem como a percepção de um aluno com deficiência visual.

\section{Resultados e discussão}




\section{HORIZONTES - REVISTA DE EDUCAÇÃO}

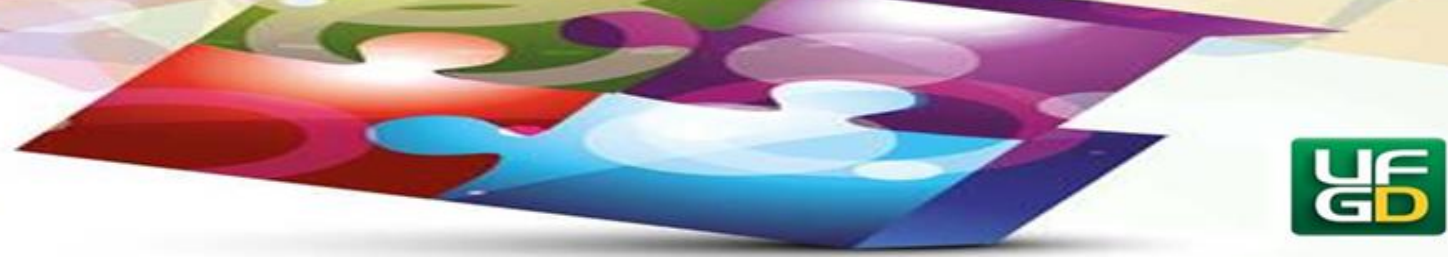

A ideia do projeto "Olhos da Alma" veio depois de uma viagem para a Tailândia do professor e Mestre em Muay Thai Alex Paraná. Quando chegou no país, ele ainda não havia tido referência local, logo teve que analisar o esporte como um todo, comparando movimentação dos praticantes locais com a movimentação que é realizada no desenvolvimento das aulas dessa modalidade no Brasil. Dessa forma, ele padronizou as movimentações, criou sequências, separou os movimentos, e assim montou cada golpe.

Essa maneira de sistematização da atividade possibilitou ao professor saber quantos movimentos cada golpe possuía como seria realizada a entrada e a finalização, sempre dividindo os golpes em partes. Após ter adquirido essa forma de trabalho na Tailândia, Alex começou a aplicar essa teoria com alunos videntes no Brasil, e constatou o sucesso da metodologia criada. Certo dia, Alex percebeu que essa didática serviria para ensinar o Muay Thai aos deficientes visuais, e assim nasceu o projeto "Olhos da Alma”. Quando começou a ensinar apenas por meio da fala e audição, Alex percebeu que os movimentos obtidos com os alunos deficientes eram os mesmos realizados pelos alunos videntes, confirmando assim que sua forma de trabalho era eficaz para fazer um deficiente visual aprender a modalidade.

Há cerca de um ano e meio o projeto está sendo realizado em Cuiabá-MT. O professor começou com 10 alunos assíduos, que ainda estão realizando as aulas. As aulas começam com uma breve explanação sobre o Muay Thai enquanto cultura, seguida da aprendizagem da saudação que os praticantes da luta realizam. O intuito dessa apresentação, conta Alex, é para que o aluno entenda um pouco da tradição que permeia a modalidade. Após esta etapa é realizado um alongamento, com alguns movimentos que colocam pontos de pressão (como queixo no ombro, dedo na ponta da sobrancelha), específicos para a aprendizagem do posicionamento da cabeça e da mão na realização dos golpes. Também são feitos alongamento da perna de apoio, (trabalhado o senso de direção com movimentos rápidos para direita e esquerda). A sessão prossegue com o aquecimento com golpes de Muay Thai, como chutes e joelhadas no saco. Também é realizado o polichinelo (com as mãos espalmadas na parede, sem perder o contato), flexões abdominais com a perna elevada (segurando o saco de pancada). Alex explica que, como os deficientes visuais não têm tanto equilíbrio, é muito importante que o abdômen esteja fortalecido. 


\section{HORIZONTES - REVISTA DE EDUCAÇÃO}

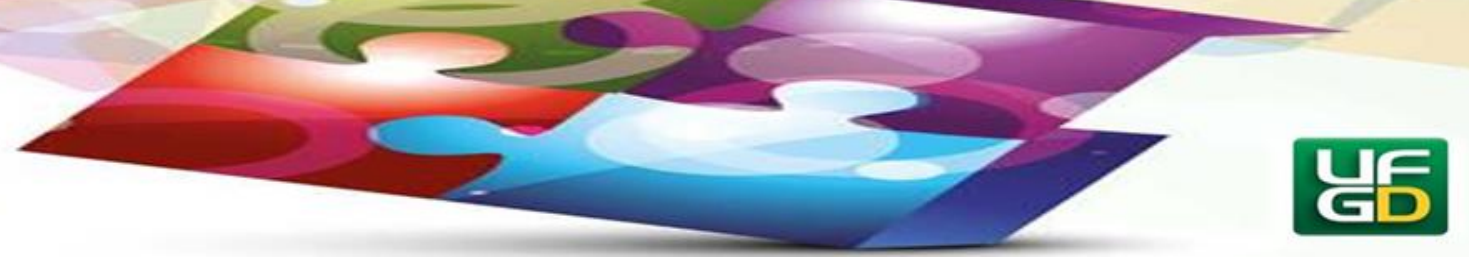

Quando perguntado sobre as técnicas utilizadas para ensinar os movimentos aos deficientes visuais, a resposta do professor foi: "Peço para eles colocarem o dedo na ponta da sobrancelha, queixo encostado no ombro, cotovelo colado na região lateral do tronco, são algumas técnicas para ensinar algumas posições para eles, porque como eles não têm o senso de direção, eles precisam sentir o corpo em movimento, tem que facilitar totalmente o movimento, para ele sair naturalmente, por isso ensino a colocar um ponto de pressão no cotovelo, pressionando a lateral do tronco, e vai fazer o giro, o queixo encostado no ombro que vai possibilitar que a coluna fique ereta, o ombro reto que tem que manter para ajudar a acertar o golpe e para não perder a defesa da mão da frente. Tudo isso foi criado para facilitar a aprendizagem do Muay Thai, e o movimento em si, utilizando a linguagem corporal."

Esse tipo de técnica, de massificação dos pontos de pressão, foi desenvolvido para facilitar a aprendizagem dos mesmos movimentos que os videntes realizam com o joelho, a ponta dos pés, um chute alongado, movimentação do braço, etc. Assim, Alex não fez qualquer modificação nos movimentos originais do Muay Thai.

O trabalho do projeto "Olhos da Alma" é para que os movimentos saiam com perfeição, porque, segundo Alex, "esse é o esporte dos deficientes visuais, não é um esporte de contato, mas sim um esporte voltado à beleza do movimento, desenhar os golpes, com os movimentos saindo totalmente alongados, buscando ainda mais a perfeição". Está nos planos do professor criar um campeonato de Muay Thai para os deficientes visuais, com apresentações cujo objetivo será ver quem consegue desenhar melhor os movimentos, como já existe no Kung Fu, uma dança de desempenho de movimento, e não a luta em si.

O único equipamento específico para o projeto é a venda nos olhos, pois existem alguns que apresentam cegueira total e outros com cegueira parcial. Dessa forma, o uso da venda visa igualar todos ao mesmo nível, impedindo vantagem para qualquer participante. Nas aulas do professor Alex, o uso da venda nos olhos é obrigatório, do início ao fim da aula, mesmo que o aluno possua perda de $100 \%$ da visão. Este recurso comenta Alex, possibilita até que praticantes videntes possam participar das aulas. Em relação aos equipamentos próprios da modalidade, não é necessário fazer nenhuma adaptação, e geralmente o único equipamento que não pode faltar é o saco de pancada, grande e pesado, pois é nele que os alunos terão apoio.

Com relação ao acompanhamento dos alunos nas aulas, o professor não vê necessidade de mais de um profissional comandando a aula, entretanto, isto se faz necessário numa situação 


\section{HORIZONTES - REVISTA DE EDUCAÇÃO}

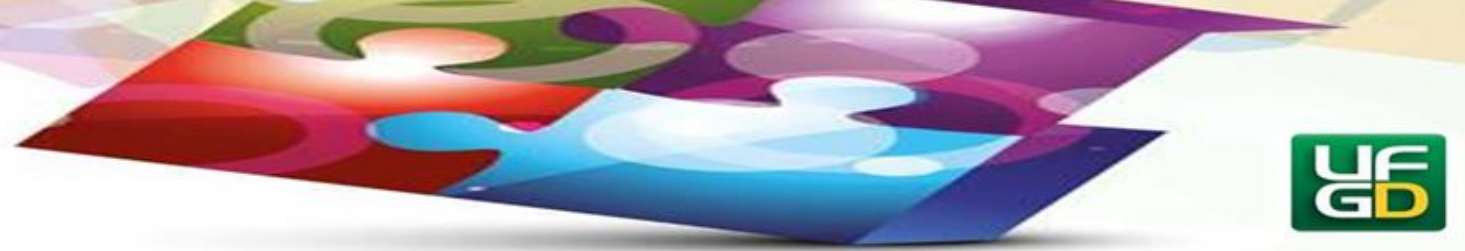

onde haja um aluno iniciante. $\mathrm{O}$ iniciante precisa de exclusividade precisa ser ensinado passoa-passo, e não há como ministrar a aula aos veteranos e ao mesmo tempo ensinar o básico a um aluno novo. Alex aponta que, quando os alunos veteranos já têm algum tempo de aula, eles conseguem auxiliá-lo na direção da aula para outros alunos do projeto, fazem a movimentação do saco e realizam a própria contagem e marcação. Isso possibilita que, em alguns casos, o professor consiga ministrar a aula para um grupo misto.

Com os métodos aplicados nas aulas do projeto "Olhos da Alma", também foram percebidas melhoras no condicionamento físico e na socialização dos participantes. A dedicação e empenho que os alunos têm nas aulas os tornaram referência na academia Thai Paraná, pois eles levam muito mais a sério o esporte e detalham mais os movimentos do Muay Thai do que os alunos videntes, segundo Alex. A visão, explica se não soubermos utilizá-la, ela tira o foco, e os deficientes visuais são extremamente focados, porque o único comando ao qual eles se conectarão é a audição.

O benefício mais nítido e rápido que o Muay Thai proporciona para os deficientes visuais, segundo o professor Alex, é a melhora da autoestima. "As pessoas com deficiência visual acabam se sentindo excluídas da sociedade, e isso faz com que elas sejam mais propensas à depressão. Porém, quando eles conseguem enxergar o mundo com os olhos da alma, conseguem notar que são pessoas comuns e que dali pra frente só depende deles, porque o que faltava é alguém para ensiná-los, porque eles são capazes. Isso gera uma autonomia também, porque um aluno do projeto pode puxar uma aula para videntes com a metodologia que aprendeu que é igual à dos videntes, e isso faz com que eles sintam que independente da deficiência que possuem, eles são normais. Isso é a inclusão social na pratica que o esporte consegue proporcionar aos alunos participantes do projeto".

A aprendizagem do aluno sobre os movimentos, golpes e posicionamento corporal varia de aluno para aluno, porém, segundo Alex, geralmente em quatro aulas o aluno já consegue realizar movimentos como jab, direto, golpes com o cotovelo, joelho, chutes, e realizar o paô, mesmo sem a perfeição necessária.

Foi perguntado ao professor sobre o financiamento do projeto, se existe algum apoio ou auxílio governamental para sua realização. A resposta foi negativa: "Todos os projetos que realizo como "Olhos da Alma", "Movimento Thai para Cadeirante” e "Thai Libras", todos são desenvolvidos pela Thai Paraná, e não existe nenhuma ajuda governamental, e por escolha 


\section{HORIZONTES - REVISTA DE EDUCAÇÃO}

e-ISSN: 2318-1540

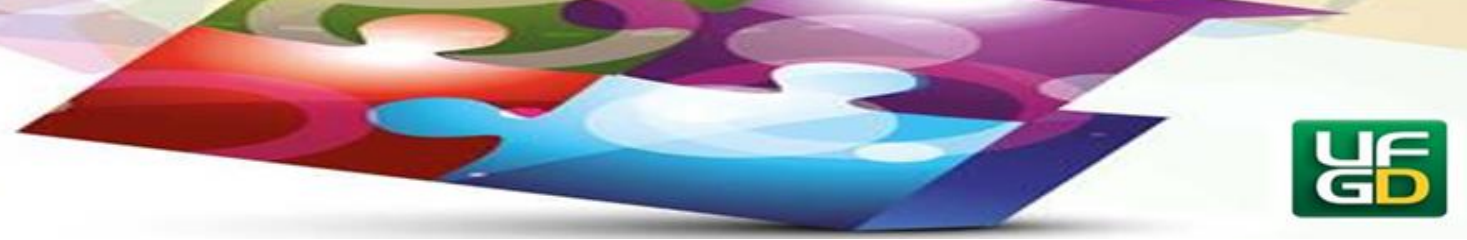

própria. Já ofereceram, mas como eu acredito que pra uma coisa nunca parar, tem que depender de você, então eu optei a fazer tudo sozinho. Não dependendo do governo, o projeto não fica à mercê da verba, pois caso contrário, correia o risco de a verba não chegar e o projeto acabar. Seria muito injusto eu dar um sonho pra eles, só que depois de um tempo ter que parar o sonho porque o governo não está bancando o projeto, porque eles não pediram para dar nenhum sonho a eles, se eu estou dando algum sonho, é responsabilidade minha continuar. Agora está sendo aprovado um projeto que vai liberar 17 milhões destinados a esses três projetos: Olhos da alma, Thai Cadeirantes e Thai Libras, eles querem esses projetos, porque são únicos no mundo e é um diferencial. No projeto eu quero fazer uma academia na arena Pantanal, onde teve a copa do mundo, aí vamos trazer mais pessoas. Neste caso seria inviável realizar esse projeto sem a ajuda do governo. Esse projeto proporcionará uma academia montada toda preparada pra eles, sem degrau, com rampa, vai ser aperfeiçoada a arena Pantanal, onde vai ser dada assistência às pessoas da terceira idade, cadeirantes, deficientes visuais e auditivos".

O projeto é divulgado por meio de televisão, rádio e jornal. O professor Alex Paraná conhece muitas pessoas da mídia local, o que facilita e viabiliza a expansão do projeto na cidade. O projeto é bem apoiado em relação à divulgação por parte da mídia, e o projeto "Olhos da Alma" também possui facebook e fanpage para expandir a divulgação por meio da internet. A aluna Luiza Santos se dispôs a responder algumas perguntas, e quando questionada sobre a importância do projeto "Olhos da Alma" na sua vida, disse que o projeto melhorou muito sua autoestima, porque diferentemente do que as pessoas pensam o projeto "Olhos da Alma" não é só luta, diz, mas toda uma interação entre espírito, corpo, mente. Segundo ela, a metodologia que é passada para a turma é muito eficaz e a aprendizagem é natural e rápida. Depois que começou a participar das aulas, sua autoconfiança para andar na rua aumentou bastante, bem como sua desenvoltura.

No dia-a-dia, Luiza também percebe muitas melhoras desde que começou as aulas. $\mathrm{O}$ desempenho no trabalho melhorou bastante, em casa com a família o relacionamento melhorou, e também com os amigos. Luiza sofre muito preconceito no cotidiano por ter baixa visão, e tinha dificuldade para lidar com isso. Ela aponta que as pessoas só entendem como cegos os que usam bengala ou têm cegueira total, assim, pessoas com baixa visão não são bem vistas, porque as pessoas não acreditam que a pessoa possui cegueira, acham que ela está fazendo 


\section{HORIZONTES - REVISTA DE EDUCAÇÃO}

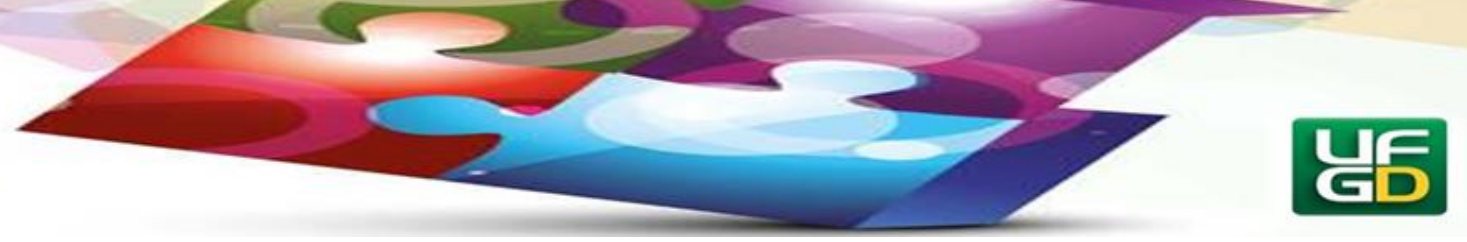

“corpo mole”. Luiza diz: "Depois que comecei a praticar o Muay Thai, consegui superar esse preconceito e lidar bem melhor com essa questão. O condicionamento físico também melhorou, percebo a diferença em coisas simples do dia-a-dia, como não me cansar mais subindo escadas, o que não era possível anteriormente, e conseguir carregar mais sacolas do mercado para a casa do que as que conseguia carregar antes".

A participação no projeto "Olhos da Alma" foi motivada pela curiosidade, mesmo não entendendo e não conseguindo imaginar, inicialmente, como seriam desenvolvidas as aulas e como funcionaria o projeto. Depois, no decorrer do trabalho e com o desenvolvimento diário, Luiza começou a gostar bastante, a participar melhor, a compreender o projeto e ver o quanto ele é importante em seu cotidiano.

Luiza conheceu o projeto por meio de um contato feito pelo professor Alex Paraná com a AMC (Associação Mato-Grossense dos Cegos). Após o contato do professor, a psicóloga da associação fez o convite aos associados, e alguns deles, como ela, aceitaram e decidiram participar do projeto.

É inegável a importância do esporte na vida dos deficientes visuais, sua relevância no cotidiano dessas pessoas e seu papel como ferramenta de inclusão social. Almeida (2007), ao relatar entrevista com David Farias Costa, na época presidente da CBDC (Confederação Brasileira de Desportos para Cegos), corrobora com a percepção de Alex, tendo afirmado que o principal papel do esporte na vida das pessoas com deficiência visual é a inclusão social. O auto cita também que através da prática esportiva, o deficiente visual sente que pode se dedicar, ser bom e ter sucesso na vida, da mesma forma que os videntes.

As percepções e sentidos utilizados na aprendizagem de uma modalidade esportiva, seja ela o Muay Thai ou qualquer outra, são as percepções auditivas e sinestésicas, construídas baseando-se na leitura do jogo/combate (MORATO, 2011). A não utilização da informação visual dá ao esporte para cegos uma dinâmica única, fato que pressupõe um entendimento tático-técnico diferenciado e a necessidade da criação de estratégias que de em suporte a isso (MORATO, 2011), e a metodologia do professor Alex Paraná tem atendido a este critério.

Sobre a percepção sinestésica, Almeida (2009) afirma que cinestesia é a sensibilidade para perceber os movimentos musculares ou das articulações e esta percepção nos torna consciente da posição e do movimento do corpo. O autor diz que os principais elementos da percepção sinestésica são consciência corporal (lateralidade, dominância, equilíbrio), imagem 


\section{HORIZONTES - REVISTA DE EDUCAÇÃO}

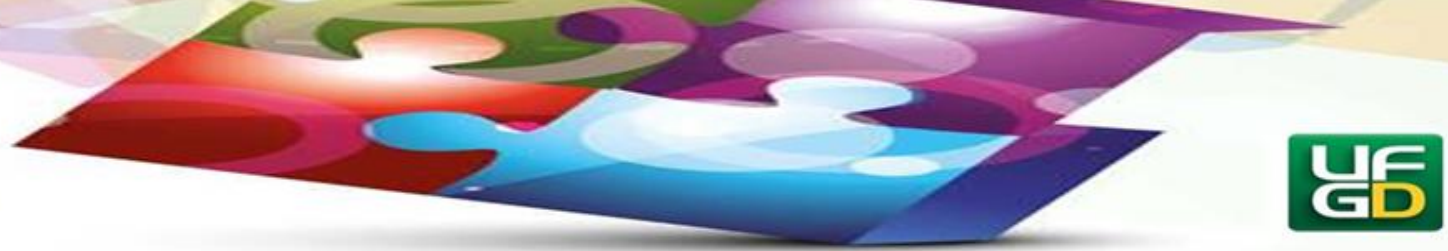

corporal e relação do corpo com os objetos que se encontram no mesmo espaço que ele. No trabalho de Alex no "Olhos da Alma" é nítida a valorização desses aspectos. Ele demonstra preocupação com o equilíbrio e a lateralidade dos alunos, buscando trabalhar e realizar exercícios que possam fortalecer a musculatura do tronco, auxiliando diretamente o equilíbrio, gerando estabilidade para aplicar os golpes e movimentos exigidos.

Alguns teóricos chegaram a supor que, em face da deficiência visual, haveria um melhor desenvolvimento de outros sentidos, um aumento na acuidade auditiva, por exemplo, (SOUZA et al., 2005). Entretanto, parece que indivíduos cegos somente desenvolvem essa habilidade quando empreendem esforços para a superação da restrição estrutural imposta pela cegueira, o que evidencia mais uma vez o importante papel do esporte na vida dessas pessoas (SOUZA et al., 2005).

Quando se trata de esportes de combate, como Karatê, Taekwondo, Jiu-Jitsu, e Judô, alguns aspectos que podem ser melhorados com a prática deste tipo de modalidade são o medo, a angústia, a ansiedade e o nervosismo (RUSSO JÚNIOR e SANTOS, 2001). Barreira e Massimi (2002) ressaltam também a melhoria nas capacidades de percepção, execução e decisão, aumentando a segurança e a autoconfiança, o que consequentemente traria impacto positivo na integração dos deficientes visuais com outras pessoas. Assim, o esporte agrega não só o conteúdo motor, mas também social e cognitivo. Já que o equilíbrio emocional e as capacidades cognitivas são imprescindíveis para a prática dos esportes de combate, acredita-se que a participação em projetos como o "Olhos da Alma" proporciona rico conteúdo ao desenvolvimento do deficiente visual, além de atacar a fundo alguns dos principais problemas relacionados ao cotidiano dessas pessoas (RUSSO JÚNIOR e SANTOS, 2001).

Os profissionais de Educação Física devem estar sempre preparados para atender às demandas necessárias ao trabalho com indivíduos com deficiência visual. Segundo Silva et al. (2008), toda ação pedagógica deve contemplar uma inter-relação entre o que ensinar, para que ensinar e como ensinar, e dessa forma é possível ensinar qualquer prática corporal ou esportiva para pessoas com qualquer tipo de deficiência, considerando sempre suas limitações e potencialidades.

\section{Conclusão}




\section{HORIZONTES - REVISTA DE EDUCAÇÃO}

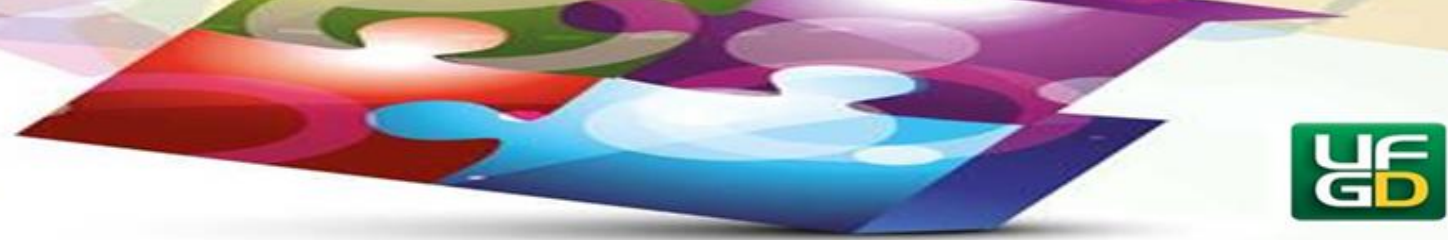

O ensino do Muay Thai para deficientes visuais desenvolvido por Alex Paraná no projeto "Olhos da Alma" possui metodologia específica desenvolvida por ele. Os movimentos foram divididos em partes, e as sequências sistematizadas. Algumas técnicas foram desenvolvidas para possibilitar o aprendizado da modalidade pelos deficientes visuais, entretanto, nenhuma adaptação precisou ser feita nos equipamentos normalmente utilizados por pessoas sem deficiência nos treinos desta modalidade. A participação no projeto, de acordo com a percepção do profissional e da aluna, contribui para a inclusão social, melhora do condicionamento físico, da socialização e da autoestima das pessoas com deficiência visual.

\section{Referências}

ALMEIDA, J.J.G.D.; GORLA, J.I. A Expressão de uma Atividade Esportiva: O desporto para cegos. Revista Conexões, v.5, n.1, p.108-113, 2007.

ALMEIDA, O.M.; SILVA, R.F.D. Atividade motora adaptada e desenvolvimento motor: possibilidades através das artes marciais para deficientes visuais. Movimento \& Percepção, v.10, n.14, p.222-239, 2009.

ARAÚJO, A.P.; MARQUES, E.S.; OLIVEIRA, M.L.A.; SILVA, E.F. Portadores de necessidades especiais: o caso do instituto de educação e reabilitação dos cegos do Rio Grande do Norte. Revista Digital de Biblioteconomia e Ciência da Informação, v.5, n.2, p.67$86,2008$.

BARREIRA, C.R.A.; MASSIMI, M. A Moralidade e a Atitude Mental no Karate-do no Pensamento de Gichin Funakoshi. Memorandum, v.2, p.39-54, 2002.

COSTA, A.M.; SOUSA, S.B. Educação física e esporte adaptado: história, avanços e retrocessos em relação aos princípios da integração/inclusão e perspectivas para o século XXI. Revista Brasileira de Ciências do Esporte, v.25, n.3, p. 27-42, 2004.

LABRONICI, R.H.D.D.; CUNHA, M.C.B.; OLIVEIRA, A.S.B.; GABBAI, A.A. Esporte como fator de integração do deficiente físico na sociedade. Arquivos de Neuropsiquiatria, v.58, n.4, p.1092-1099, 2000.

MACIEL, M.R.C. Portadores de deficiência e a questão da inclusão social. Revista São Paulo em Perspectiva, v.4, n.2, p.51-56, 2000.

MAGALHÃES, C.P.; NASCIMENTO, C.; GUIMARÃES, D.; OLIVEIRA, N.C. Percepção e expectativas do esportista com deficiência em relação ao profissional de Educação Física. Lecturas Educación Física y Deportes, v.19, n.199, p.1-5, 2014. 


\section{HORIZONTES - REVISTA DE EDUCAÇÃO}

e-ISSN: 2318-1540

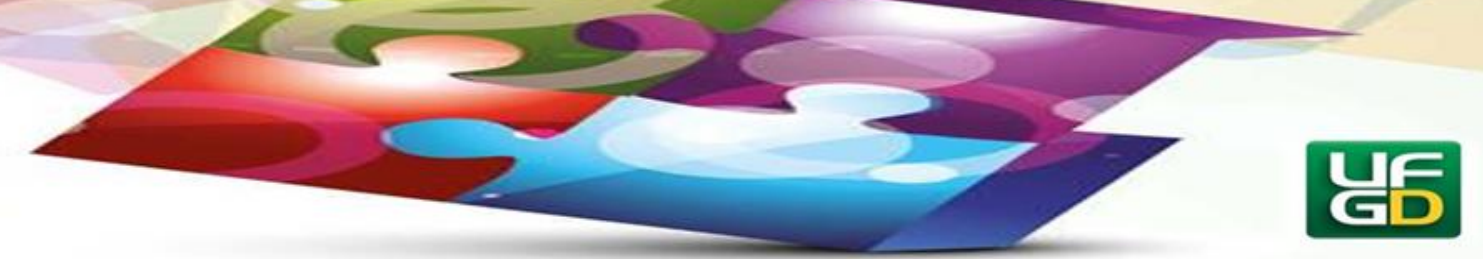

MORATO, M.P.; GOMES, M.S.P.; DUARTE, E.; ALMEIDA, J.J.G.D. A leitura de jogo no futebol para cegos. Movimento, v.17, n.3, p.97-114, 2011.

OLIVEIRA, L.M.B.; Cartilha do Censo 2010 - Pessoas com Deficiência. Coordenação-Geral do Sistema de Informação sobre a Pessoa com Deficiência. Brasília, 2012.

SOUZA, C.M.D.; OLIVEIRA, C.W.; FERREIRA, A.C.G.O.; ALMEIDA, J.J.G. A Educação Física e suas contribuições em um programa de orientação e mobilidade para crianças deficientes visuais. Lecturas: Educación Física y Deportes, v.10, n.09, p.1, 2005.

PEREIRA, R.; OSBORNE, R.; PEREIRA, A.; CABRAL, S.I. A importância do desporto de alto rendimento na inclusão social dos cegos: Um estudo centrado no instituto Benjamin Constant-Brasil. Motricidade, v.9, n.2, p.95-106, 2013.

RUSSO JÚNIOR, W.; SANTOS, L.J.M. O Judô como atividade pedagógica desportiva complementar, em um processo de orientação e mobilidade para portadores de deficiência visual. Lecturas: Educación Física y Deportes, v.7, n.35, p.1, 2001.

SILVA, R.F.D.; SEABRA JÚNIOR, L.; ARAÚJO, P.F.D. Educação Física Adaptada no Brasil: da História à Inclusão Educacional. São Paulo: Phorte Editora, 2008.

VIEIRA, C.S. Influência da prática do judô no comportamento ansioso de adolescentes cegos. Dissertação de Mestrado, Universidade Estadual do Rio de Janeiro, Rio de Janeiro, 1998.

\section{Apêndice}

\section{Roteiro da Entrevista}

\section{Perguntas ao professor}

- Como surgiu a ideia do projeto olhos da alma?

- Há quanto tempo esse projeto está sendo realizado?

- Como são desenvolvidas as aulas e a sequência das atividades?

- Quais são as técnicas utilizadas para ensinar os movimentos ao deficiente visual?

- Foi necessário fazer adaptações nos movimentos? Quais?

- Como você elaborou o método de ensino para os deficientes visuais?

- É necessária a utilização de algum equipamento específico?

- É necessário fazer adaptações nos equipamentos?

- É necessário ter mais de um profissional durante as sessões com os deficientes visuais?

- O método aplicado tem produzido melhora no condicionamento físico e na inclusão social dos alunos?

- Quais são os benefícios que o MuayThai proporciona aos deficientes visuais?

- Por que se utiliza a venda nos olhos?

- Quanto tempo leva para os alunos conseguirem praticar o esporte? 


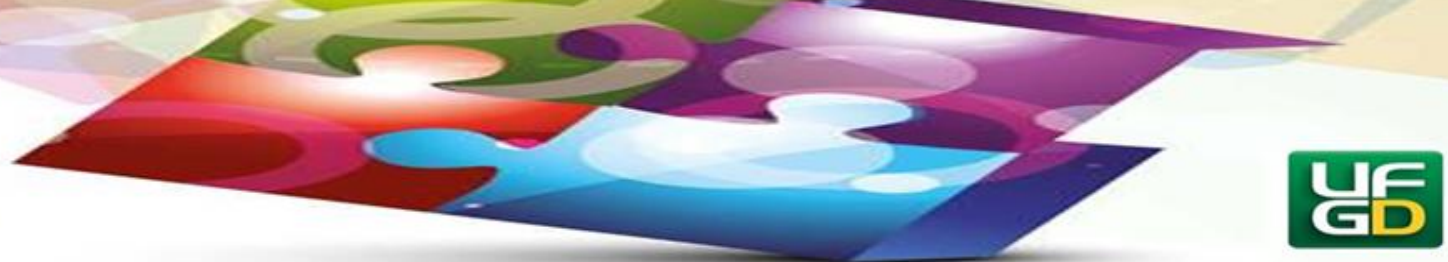

- Você recebe algum auxílio governamental para o projeto?

- Quantos deficientes visuais o projeto já conseguiu alcançar?

- De que maneira você divulga o projeto entre o seu público-alvo?

\section{Perguntas à aluna}

- Qual a importância do projeto "Olhos da Alma" na sua vida?

- O que melhorou no seu dia-a-dia desde que você começou a participar do projeto?

- Você considera que seu condicionamento físico melhorou?

- Por que você decidiu participar do projeto "Olhos da Alma?

- Como você conheceu o projeto "Olhos da Alma?

Enviado : 28/02/2018

Aceito : 01/08/2018 